\title{
Sodium Hydroxide Pretreatment and Enzymatic Hydrolysis of Oil Palm Mesocarp Fiber
}

\author{
Nur Izzati Iberahim, Jamaliah Md Jahim, Shuhaida Harun, Mohd Tusirin Mohd Nor, and Osman Hassan
}

\begin{abstract}
Sodium hydroxide pretreatment of oil palm mesocarp fiber (OPMF) was carried out with $\mathrm{NaOH}$ from $2 \%$ to $10 \%(\mathrm{w} / \mathrm{v})$ at temperature $50^{\circ} \mathrm{C}$ and $70^{\circ} \mathrm{C}$. The performances of pretreatments were evaluated based on total carbohydrate and reducing sugar including glucose, xylose and arabinose after enzymatic hydrolysis on the pretreated biomass. It was found that the enzymatic hydrolysis had significantly improved when $6 \% \mathrm{NaOH}$ in $70^{\circ} \mathrm{C}$ applied in the pretreatment process. The highest total reducing sugars produced by means of commercial enzymes was achieved with the overall conversions of glucan and xylan of $87 \%$ and $60.73 \%$ respectively. The compositions of OPMF in this study are as follows $(\% \mathrm{~g} / \mathrm{g}$ dry biomass): glucan, 28.8, xylan, 25.3, arabinan, 1.91, ethanol extractive, 6.32 and ash, 2.60.
\end{abstract}

Index Terms-Enzymatic hydrolysis, glucose, $\mathrm{NaOH}$ pretreatment, oil palm mesocarp fiber.

\section{INTRODUCTION}

At present, most of the world's production of palm oil comes from South-East Asia. Malaysia is the second largest contributor and exporter in the palm oil industry [1]. About 5 million hectares of oil palm planted area emerged in 2011 was as result of planted area increases in Sabah and Sarawak [2].

The palm oil industry generates large volume of lignocellulosic biomass from the oil extraction process. Solid biomass such as oil palm mesocarp fiber (OPMF) is an attractive feed stock because it is an abundant, renewable source, rich with various carbohydrate sugars and other useful chemical compounds that can be converted into a range of value added products. Due to the enormity of the plantation industry, about 10.9 million tons of oil palm mesocarp fiber is being produced annually as agriculture waste and contributes to the accumulation of lignocellulosic waste and cause emission of greenhouse gas to the environment [1]. Traditionally oil palm mesocarp fiber is either used in mulching or incinerated, however both

Manuscript received February 9, 2013; revised April 12, 2013. This work was supported by Universiti Kebangsaan Malaysia (UKM).

Nur Izzati Iberahim, Jamaliah Md Jahim, and Shuhaida Harun are with the Department of Chemical and Process Engineering, Faculty of Engineering and Built Environment, Universiti Kebangsaan Malaysia (UKM), $43600 \quad$ Bangi, Selangor, Malaysia. (e-mail:nurizzatiberahim@gmail.com, jamal@eng.ukm.my, suhaida@eng.ukm.my)

Mohd Tusirin Mohd Nor is with the UKM-YSD-Chair for Sustainable Development of Palm Oil Processing, Faculty of Engineering and Built Environment, Universiti Kebangsaan Malaysia (UKM), 43600 Bangi, Selangor, Malaysia. (e-mail: tusirin@eng.ukm.my)

Osman Hassan is with the School of Chemical Sciences and Food Technology, Faculty of Science and Technology, Universiti Kebangsaan Malaysia (UKM), 43600 Bangi, Selangor, Malaysia. (e-mail: osman@pkrisc.cc.ukm.my) methods are detrimental to the environment thus a more sustainable method is required.

Generally, lignocellulosic biomass consists of three main groups of polymer that are cellulose, hemicelluloses and lignin [3]. These compounds are also major components in oil palm biomass [4]. Celluloses and hemicelluloses are polysaccharides of the desired carbohydrate sugar. Numbers of research and development activities were previously done in order to exploit biomass content potential and transform it into higher valued compounds [5]-[8]. In order to achieve these targets, most biomass conversion process requires pretreatment to increase the accessibility of enzyme during hydrolysis process [9]. The process to remove lignin compound from lignocellulosic biomass prior to be used for enzymatic hydrolysis and fermentation process become an important factor in order to produce suitable source fermentable substrate in the next process.

Alkaline pretreatment has been identified as one of the best chemical pretreatment methods for delignification of lignocellulosic biomass [10], [11]. This method is efficient if agricultural waste being used rather than the wood materials [12]. The critical parameters for alkaline pretreatment are reaction temperature, pretreatment time and alkali loading [13]. Apart from that, the accessibility of surface area, the presence of lignin and hemicelluloses would be the key factors affecting the rate of enzymatic hydrolysis of cellulose [14], [15].

The study aimed to investigate the best condition of sodium alkaline pretreatment that able to give efficient enzymatic hydrolysis. Hydrolysability will be evaluated through the chemical compositions of oil palm mesocarp fiber before and after the pretreatment at different percentage of $\mathrm{NaOH}$ added and the controlled temperature.

\section{MATERIALS AND MethodS}

\section{A. Biomass Preparation}

The oven dried oil palm mesocarp fiber with $5 \%$ initial moisture content was obtained from Sime Darby Palm Oil Processing Mill located at Carey Island, Selangor, Malaysia. The fibers were ground into the average size of 2-mm using a grinder (model FRITSCH UCM 19) to provide a large surface area for enzymatic reaction. The samples were stored in sealed plastic bags at room temperature until used for the pretreatment and fibers characterization.

\section{B. Pretreatment Experiment}

The pretreatment process was carried out at ambient pressure (1atm) in different concentrations of sodium hydroxide (Table I) varying from $2 \%$ to $10 \%$ (w/v) and heated at temperature $50^{\circ} \mathrm{C}$ and $70^{\circ} \mathrm{C}$ in the closed chamber. 
The ratio of biomass to liquid used in this experiment was $1: 10$ or $10 \%$ loading. After 2 hours, the resulting fibers was washed, neutralized and air dried in ambient temperature. The dried pretreated fibers were kept in a sealed plastic bag at $-8^{0} \mathrm{C}$ until used for enzymatic hydrolysis.

TABLE I: ALKALINE PRETREATMENT OF OPMF

\begin{tabular}{lcc}
\hline \hline Code & Temperature $\left({ }^{0} \mathrm{C}\right)$ & NaOH Concentration $(\% \mathrm{w} / \mathrm{v})$ \\
\hline $\mathrm{Ca}^{\mathrm{x}}$ & 50 & - \\
$\mathrm{P} 1$ & 50 & 2 \\
$\mathrm{P} 2$ & 50 & 4 \\
$\mathrm{P} 3$ & 50 & 6 \\
$\mathrm{P} 4$ & 50 & 8 \\
$\mathrm{P} 5$ & 50 & 10 \\
$\mathrm{Cb}$ & $\mathrm{x}$ & - \\
$\mathrm{P} 6$ & 70 & 2 \\
$\mathrm{P} 7$ & 70 & 4 \\
$\mathrm{P} 8$ & 70 & 6 \\
P9 & 70 & 8 \\
P10 & 70 & 10 \\
\hline \hline $\mathrm{x}$ Biomass without alkaline pretreatment (control)
\end{tabular}

x Biomass without alkaline pretreatment (control)

\section{Enzymayic Hydrolysis}

The enzymatic hydrolysis of pretreated fibers was carried out in $250 \mathrm{~mL}$ Erlenmeyer flasks in an incubator shaker (ECOTRON EC 25) set at $50^{\circ} \mathrm{C}$ and $150 \mathrm{rpm}$. About 5 gram (dry basis) of pretreated fibers was immersed in $0.05 \mathrm{M}$ sodium citrate buffer to maintain a desired $\mathrm{pH}$ of 4.8 . The enzymes, Cellulase (Celluclast 1.5L, Novozymes A/S, Denmark) and cellobiase (Novozym 188, Novozymes A/S, Denmark) was added at 60 FPU per g glucan loading (FPU = filter paper unit) and 64 pNPGU per g glucan (pNPG = p-Nitrophenyl $\beta$-D-glucoside) and incubated for 72 hours. The activities of the enzymes were measured using standard procedures as in [16]. The filter paper activity of Celluclast $1.5 \mathrm{~L}(85 \mathrm{FPU} / \mathrm{ml})$ was determined according to the method as in [17] while $\beta$-glucosidase activity of Novozyme 188 (1946 pNPGU/ml) was determined according to the method as in [18]. The hydrolysates were filtered before it was stored at $-8^{0} \mathrm{C}$ for sugar determination.

\section{Analytical Method}

The composition of oil palm mesocarp fiber such as extractives and ash was determined according to the laboratory analytical procedure, LAP [19]. The extractives for both raw and pretreated fibers were analyzed for monomeric sugars such as glucose, xylose and arabinose. Other than that, ethanol extractive and lignin including acid insoluble lignin (Klason lignin) and acid soluble lignin were analyzed. The sugars monomer of raw and pretreated fibers were determined using high performance liquid chromatography, HPLC system (Model G1311A, Agilent Technologies) with refractive index detector and Rezex ROA column, (dimension of column $50 \times 7.8 \mathrm{~mm}$; flow rate of 0.6 $\mathrm{mL} / \mathrm{min}$; temperature at $60^{\circ} \mathrm{C}$ ). The amount of $30 \mu \mathrm{L}$ aliquots of $0.45 \mu \mathrm{m}$ filtered sample were injected into the HPLC system. The hydrolysate samples composed of monomeric sugars were measured with another HPLC system (Model Waters 1525) equipped with a column (Merck Purosther, $\mathrm{NH}_{2}$ ) and ELSD detector. The column was operated at ambient temperature using mobile phase of HPLC grade acetone nitrile and deionised water at ratio 80:20 with flow rate of $1.0 \mathrm{~mL} / \mathrm{min}$. Total reducing sugars and total carbohydrates were determined by dinitrosalicylic acid (DNS) reagent and phenol sulphuric acid assay, respectively. The untreated, treated and hydrolysed fibers were sent to SEM (scanning electron microscopy model EVO MA10 (CARL ZEISS, UK)) analysis for the observation of biomass structure. Prior to the SEM analysis, the oven dried samples were prepared by applying $2.5 \mathrm{~nm}$ thickness gold coating using sputter coater system Model Q150 RS (Quorum Technologies, UK).

\section{RESULTS AND DISCUSSION}

\section{A. Biomass Characterization}

The composition of monomeric sugar and other major components in raw oil palm mesocarp fiber is shown in Table II. Glucan was the main component in the fiber followed by xylan, arabinan and acid insoluble lignin. From the result, the amount of the majority components was lesser than those found from published data as in [4]. The composition indicates that oil palm mesocarp fiber is indeed rich in carbohydrates and a potential source of carbon for biohydrogen production.

TABLE II: COMPOSITION OF THE RAW OPMF

\begin{tabular}{ll}
\hline Composition & Content $(\%)$ \\
\hline Glucan & $28.8 \pm 0.48$ \\
Xylan & $25.3 \pm 0.65$ \\
Arabinan & $1.91 \pm 0.12$ \\
Acid Insoluble Lignin (AIL) & $28.97 \pm 2.07$ \\
Ash & $2.6 \pm 0.34$ \\
Ethanol Extractive & $6.32 \pm 0.51$ \\
\hline \hline
\end{tabular}

\section{B. Effect of $\mathrm{NaOH}$ Pretreatment on Compositional Changes of $O P M F$}

Table III represents the change of fiber composition with different reaction temperature and different percentage of added $\mathrm{NaOH}$ during pretreatment process. As indicated by sample P8, around $23.7 \%$ of acid insoluble lignin was removed when treated with $6 \% \mathrm{NaOH}$ at $70^{\circ} \mathrm{C}$ and the amount was further increased when the fiber was treated with $8 \%$ and $10 \% \mathrm{NaOH}$ at $70^{\circ} \mathrm{C}$. The total weight loss of each component (as shown in the parentheses) is mainly attributed to the extractive being removed during the pretreatment process. Apart from that, by increasing sodium hydroxide concentration from $2 \%$ to $10 \%$ and reaction temperature from $50^{\circ} \mathrm{C}$ to $70^{\circ} \mathrm{C}$, gave significant effect on lignin degradation by 4-folds that was from $7.5 \%$ to $27.4 \%$.

As shown in Table III, pretreatment could cause the loss in cellulose by less than $7.5 \%$ for all experiments. However, as it can be seen, the degradation of hemicelluloses was quite significant and highest loss was obtained by pretreatment in $10 \%$ sodium hydroxide. This result indicates that hemicellulose is more vulnerable when using this pretreatment process compared to cellulose [20]. Previous works done by [21] and [9] also agree that, alkaline pretreatment could cause cellulose fibers to swell rather than directly degrading it. They concluded that this pretreatment is the best method to avoid further fragmentation of 
hemicelluloses polymers as well as break up the ester bonds between lignin, hemicelluloses and cellulose [22].

It should be noted that the amount of total reducing sugar and total carbohydrate especially in the black liquor of the hemicelluloses portion was quite high. It was found that higher $\mathrm{NaOH}$ concentration caused increased amount of chemical component available in the black liquor as shown in Fig. 1 and Fig. 2. The previous study has shown by [23], [24] that the extracted xylan from the black liquor contains functional oligosaccharides that are proven to be effective in enhancing human immune system, as dietary fiber-like action, antioxidant and antibiotic alternative [25], [26].

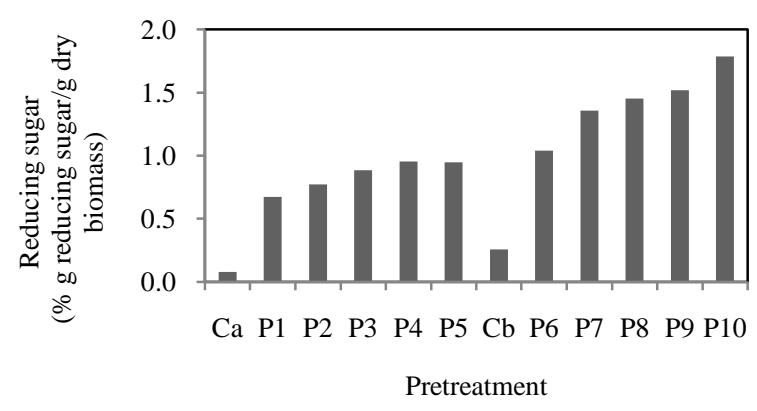

Fig. 1. Total reducing sugars production in black liquor with different $\mathrm{NaOH}$ pretreatment condition.

TABLE III: COMPOSITION OF SODIUM HydROXIDE PRETREATED OPMF AT DIFFERENT TEMPERATURE AND CONCENTRATION

\begin{tabular}{|c|c|c|c|c|}
\hline \multirow[b]{2}{*}{ Pretreatment } & \multicolumn{4}{|c|}{ Composition of solids fractions ${ }^{\mathrm{x}, \mathrm{y}}$ (g/100 g initial dry biomass) } \\
\hline & Lignin & Glucan & Xylan & Arabinan \\
\hline $\mathrm{Cn}$ & 29.01 & 28.79 & 25.29 & 1.91 \\
\hline P1 & $26.85(7.46 \%)$ & $28.02(2.70 \%)$ & $23.91(5.49 \%)$ & $1.76(7.92 \%)$ \\
\hline $\mathrm{P} 2$ & $26.03(10.26 \%)$ & $27.71(3.76 \%)$ & $22.19(12.27 \%)$ & $1.65(13.67 \%)$ \\
\hline P3 & $25.66(11.56 \%)$ & $27.53(4.38 \%)$ & $23.35(7.70 \%)$ & $1.67(12.39 \%)$ \\
\hline P4 & $23.70(18.31 \%)$ & $27.24(5.41 \%)$ & $21.72(14.14 \%)$ & $1.28(33.18 \%)$ \\
\hline P5 & $22.99(20.75 \%)$ & $26.89(6.62 \%)$ & $21.78(13.88 \%)$ & $1.27(33.59 \%)$ \\
\hline P6 & $24.46(15.69 \%)$ & $27.42(4.78 \%)$ & $23.91(5.47 \%)$ & $1.55(18.82 \%)$ \\
\hline P7 & $24.10(16.90 \%)$ & $27.16(5.66 \%)$ & $23.85(5.73 \%)$ & $1.24(35.01 \%)$ \\
\hline P8 & $22.14(23.68 \%)$ & $27.01(6.61 \%)$ & $18.00(28.82 \%)$ & $1.1(42.65 \%)$ \\
\hline P9 & $21.14(27.11 \%)$ & $26.76(7.08 \%)$ & $15.46(38.87 \%)$ & nd \\
\hline $\mathrm{P} 10$ & $21.05(27.44 \%)$ & $26.65(7.45 \%)$ & $16.39(35.20 \%)$ & $1.1(42.70 \%)$ \\
\hline
\end{tabular}

$\mathrm{x}$ Data are means of replicate.

y Data in parentheses are the $\%$ amount of composition removed during the pretreatment.

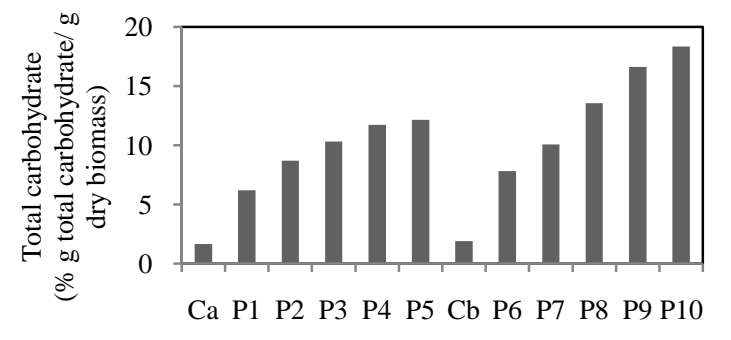

Pretreatment

Fig. 2. Total carbohydrate production in black liquor with different $\mathrm{NaOH}$ pretreatment condition

\section{Overall Conversion of Carbohudrates in OPMF}

The experimental results of enzymatic hydrolysis of oil palm mesocarp fiber by different pretreatment conditions are shown in Fig. 3. Effects of the amount of sodium hydroxide with different reaction temperature were evaluated by comparing the total reducing sugar produced after enzymatic hydrolysis process. It was observed that the pretreatment with $6 \% \mathrm{NaOH}$ in higher temperature $70^{\circ} \mathrm{C}$ yielded the highest total reducing sugar. However, further increased of $\mathrm{NaOH}$ concentration resulted decrease amount of total reducing sugar in the hydrolysate.

The results also showed that some products of the treated fiber such as glucan, xylan and arabinan was found solubilized in the black liquor during the pretreatment process at high $\mathrm{NaOH}$ concentration and high reaction temperature condition. This finding is agreeable as in [27] when they also found some factors such as temperature, concentration and treatment time are the most important manipulated parameter in the hydrolysis process in order to maintain or retain the carbohydrate sugars in the treated fiber.

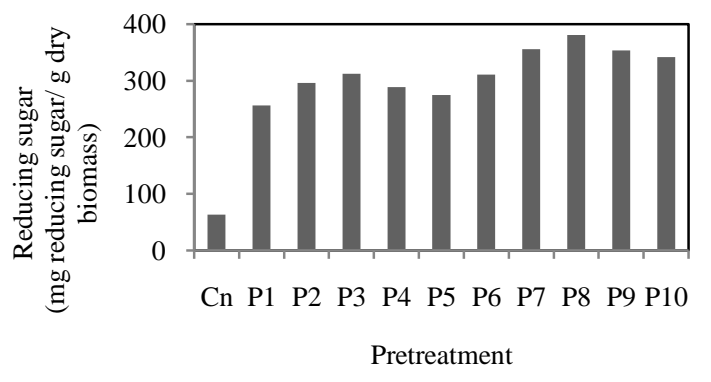

Fig. 3. Total reducing sugars production in hydrolysis process from pretreated oil palm mesocarp fibers with $\mathrm{NaOH}$ of $2 \%, 4 \%, 6 \%, 8 \%$ and $10 \%$ (w/v) at $50^{\circ} \mathrm{C}$ and $70^{\circ} \mathrm{C}$ for 2 hours. 
The overall glucan and xylan conversion after hydrolysis process were summarized in Fig. 4 and Fig. 5. It was noted that when pretreatment temperature increased to $70^{\circ} \mathrm{C}$ greater overall glucan and xylan conversion were observed. Compared to untreated fiber (control), the hydrolysis of the treated fiber had resulted in more glucan and xylan production. The rate of hydrolysis reaction was found to be more rapid with the treated fiber. This could be the reason greater fraction of oil palm mesocarp fiber hemicelluloses able to sollubilized into the black liquor after treated with $\mathrm{NaOH}$. In addition, after pretreatment it was also noted that lignin was removed and leaving the carbohydrate fraction in cellulose form [9]. Apart from that, the cellulose fraction of the fiber had swelled and changed it configuration from crystalline form to the more reactive amorphous form [28]. This transformation significantly increases the accessibility of enzyme during hydrolysis process.

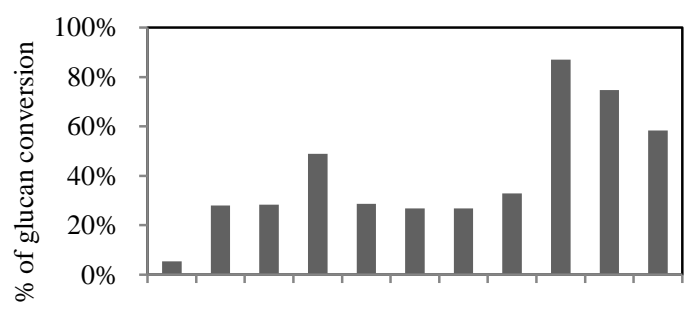

$\begin{array}{llllllllllll}\text { Cn } & \text { P1 } & \text { P2 } & \text { P3 } & \text { P4 } & \text { P5 } & \text { P6 } & \text { P7 } & \text { P8 } & \text { P9 } & \text { P10 }\end{array}$

Pretreatment

Fig. 4. The Overall conversion of glucan after 72 hours enzymatic hydrolysis of $\mathrm{NaOH}$ pretreated oil palm mesocarp fibers

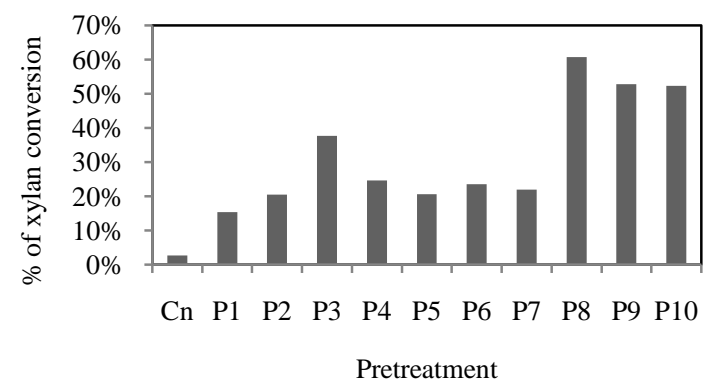

Fig. 5. The overall conversion of xylan after 72 hours enzymatic hydrolysis of $\mathrm{NaOH}$ pretreated oil palm mesocarp fibers

\section{The SEM Observation of Untreated, Treated and Hydrolyzed Fiber}

Fig. 6 represents the images of OPMF observed by scanning electron micrograph (SEM) for verification of the structural changes caused by $\mathrm{NaOH}$ pretreatment and enzymatic hydrolysis. The images taken were on raw OPMF, pretreated OPMF and hydrolyzed OPMF. It was found that the initial structure of single strand of raw OPMF covered with small particles or globules (Fig. 6(a)). This figure describes that the raw fibers consist of lignin that cemented the cellulose and hemicelluloses. The presence of lignin hinders the accessibility of enzymes, cellulase and hemicellulase from the targeted substrates, hence decreasing the effectiveness of enzyme hydrolysis.

Fig. 6(b) shows the structure of pretreated fiber with $6 \%$ of $\mathrm{NaOH}(\mathrm{w} / \mathrm{v})$ which had been transformed and the surface of the fiber had become loosened and roughened. The pores structure was formed on the fiber when the lignin was solubilized and removed by $\mathrm{NaOH}$ pretreatment. It can be observed that more severe pretreatment with higher $\mathrm{NaOH}$ concentration cause greater disruption on the fiber structure and creating number of large pores. This phenomenon significantly increases the accessibility of enzyme during hydrolysis process [3]. After the enzymatic hydrolysis, the structure mesocarp fiber was completely destroyed and wall of the fibers was completely ruptured as shown in Fig. 6(c). A parallel observation was reported as in [29] and [30].

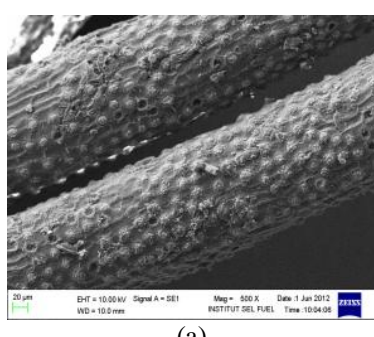

(a)

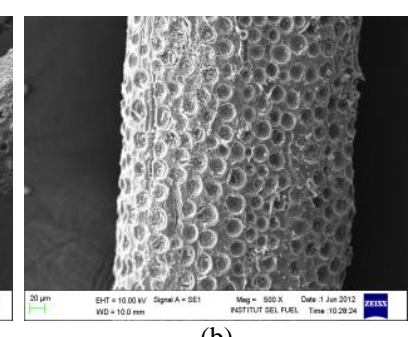

(b)

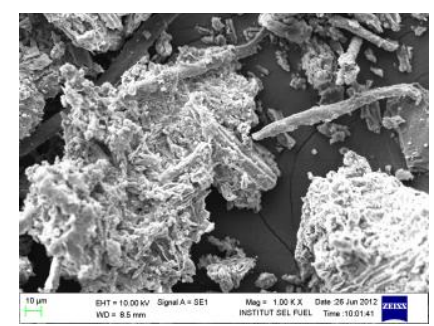

(c)

Fig. 6. Electronic scanning microscopic pictures of untreated, treated and hydrolyzed fibers, (a) OPM fibers, magnified 500x, (b) NaOH treated OPM fibers, magnified 500x, (c) Hydrolysed treated OPM fibers, magnified 1000x.

\section{CONCLUSION}

Alkaline pretreatment of oil palm mesocarp fiber by sodium hydroxide has shown capable in reducing lignin content and also enhancing enzymatic digestibility. This study showed that pretreatment at $6 \%$ of sodium hydroxide concentration at temperature $70^{\circ} \mathrm{C}$ gave the best result in the digestibility of oil palm mesocarp fiber in order to increase the total reducing sugar production during hydrolysis process. More than $90 \%$ of the cellulose retained in the treated fiber after pretreatment process with $6 \%$ of sodium hydroxide concentration at $70^{\circ} \mathrm{C}$ reaction condition. Meanwhile, $20 \%$ of the acid insoluble lignin and solubilizing $60-70 \%$ of hemicelluloses was also removed by the pretreatment. Therefore, $67 \%$ (\% g of total reducing sugar/g untreated biomass) conversion was achieved for the whole process with the overall conversion of glucan and xylan were $87 \%$ and $60.73 \%$ respectively. This study shows that this pretreatment could be applied on oil palm wastes for higher conversion in enzymatic hydrolysis that potentially to be used for various purposes.

\section{ACKNOWLEDGMENT}

The authors would like to acknowledge Universiti Kebangsaan Malaysia and UKM-Yayasan Sime Darby underprogramme Chair for Sustainable Technology Development for providing financial support for this research. 


\section{REFERENCES}

[1] S. H. Shuit, K. T. Tan, K. T. Lee and A. H. Kamaruddin, "Oil Palm Biomass as a Sustainable Energy Source: A Malaysia Case Study," Energy, vol. 34, pp. 1225-1235, September 2009.

[2] Malaysia Palm Oil Board (MPOB), Overview of the Malaysian Oil Palm Industry 2011, 2011.

[3] D. R. Keshwani and J. J. Cheng, "Microwave-Based Alkali Pretreatment of Switchgrass and Coastal Bermudagrass for Bioethanol Production," Biotechnol Prog., vol. 26, pp. 644-652, May 2010.

[4] M. A. A. Mohammed, A. Salmiaton, W. A. K. G Wan Azlina, M. S. Mohammad Amran, A. Fakhru'l-Razi, and Y. H Taufiq-Yap, "Hydrogen Rich Gas from Oil Palm Biomass as a Potential Source of Renewable Energy in Malaysia," Renewable and Sustainable Energy Reviews, vol. 15, pp. 1258-1270, February 2011.

[5] M. J. Taherzadeh and K. Karimi, "Enzymatic-Based Hydrolysis Processes for Ethanol from Lignocellulosic Materials: A Review," Bioresources, vol. 2, pp. 707-738, 2007.

[6] M. J. Taherzadeh and K. Karimi, "Acid-Based Hydrolysis Processes for Ethanol from Lignocellulosic Materials: A Review," Bioresources, vol. 2, pp. 472-499, 2007.

[7] A. Fangkum and A. Reungsang, "Biohydrogen Production from Sugarcane Bagasse Hydrolysate by Elephant Dung: Effect of Initial pH and Substrate Concentration," presented at the International Conference on Fermentation Technology for Value Added Product, FerVAAP, Thailand, August 26-28, 2009.

[8] K. Nath and D. Das, "Hydrogen from Biomass," Current Science, vol. 85, pp. 265-271, August 2003.

[9] M. J. Taherzadeh and K. Karimi, "Pretreatment of Lignocellulosic Wastes to Improve Ethanol and Biogas Production: A Review," Int. J. Mol. Sci., vol. 9, pp. 1621-1651, September 2008.

[10] M. Saritha, A. Arora, and Lata, "Biological Pretreatment of Lignocellulosic Substrates for Enhanced Delignification and Enzyme Digestibility," Indian Journal Microbiology, vol. 52, pp. 122-130, June 2012.

[11] S. Kim and M. T. Holtzapple, "Lime Pretreatment and enzymatic Hydrolysis of Corn Stover," Bioresource Technology, vol. 96, pp 1994-2006, December 2005.

[12] R. Kumar and C. E. Wyman, "Effects of Cellulase and Xylanase Enzymes on the deconstruction of Solids from Pretreatment of Poplar by Leading Technologies," Biotechnol Prog., vol. 25, pp. 302-314, March 2009.

[13] R. A. Silverstein, Y. Chen, R. R. Sharma-Shivappa, M. D. Boyette, and J. Osborne, "A Comparison of Chemical Pretreatment Methods for Improving Saccharification of Cotton Stalks," Bioresource Technology, vol. 98, pp. 3000-3011, November 2007.

[14] H. E. Grethelin, "The effect of pore size distribution on the rate of enzymatic hydrolysis of cellulosic substrates," Nature Biotechnology.,vol 3, pp 155-160, 1985.

[15] C. A. Mooney, S. D. Mansfield, M. G. Touhy, and J. N. Saddler, "The effect of initial pore volume and lignin content on the enzymatic hydrolysis of softwoods," Bioresource Technology, vol. 64, pp. 113-119, May 1998.

[16] M. Selig, N. Weiss, and Y. Ji, "Enzymatic saccharification of lignocellulosic biomass: Laboratory Analytical Procedure (LAP),' Technical Report NREL, March 2008.
[17] T. K. Ghose, "Measurement of cellulase activities," Pure \& Appl. Chem. vol. 59, pp. 257-268, 1987.

[18] H. H. Yeoh, T. K. Tan, S. L Chua, and G. Lim, "Properties of $\beta$-glucosidase purified from Aspergillus niger," MIRCEN Journal, vol. 4, pp. 425-430, February 1988.

[19] A. Sluiter, R. Hames, C. Ruiz, J. Scarlata, D. Templeton, and D. Crocker, "Determination of Structural Carbohydrates and Lignin in Biomass," Technical Report NREL/TP-510-42618, April 2008.

[20] A. S. Schmidt and A. B. Thomsen, "Optimization of wet oxidation pretreatment of wheat straw," Bioresource Technology, vol. 64, pp. 139-151, 1998.

[21] A. T. W. M. Hendriks and G. Zeeman, "Pretreatments to enhance the digestibility of lignocellulosic biomass," Bioresource Technology, vol. 64, pp.139-151, May 1998.

[22] M. Gaspar, G. Kalman, and K. Reczey, "Corn fiber as a raw material for hemicellulose and ethanol production," Process Biochemistry, vol. 42, pp. 1135-1139, July 2007.

[23] O. Akpinar, K. Erdogan, and S. Bostanci, "Enzymatic production of xylooligosaccharide from selected agricultural wastes," Journal of Food and Bioproducts Processing, vol. 87, pp. 145-151, June 2009.

[24] H. Farah Salina, A. Fazilah, M. N. Mohd Azemi, and M. H. Norziah, "Enzymatic hydrolysis and isolation of oil palm front derived xylooligosaccharide by xylanase Trichoderma viride," presented at the International Conferences on Environmental Research and Technology, ICERT, Penang, Malaysia, May 28-30, 2008.

[25] P. Seema and G. Arun, "Functional oligosaccharides: Production, properties and applications," Journal of Microbiology and Biotechnology, vol. 27, pp. 1119-1128, May 2010.

[26] K. Koga and S. Fujikawa, "Xylooligosaccharides. In: Oligosaccharides," Shizuoka, Japan: Nihon Shokuhin Kako Ltd., vol. 3, pp. 130-143, 1985.

[27] Y. Zhao, Y. Wang, J. Y. Zhu, A. Ragauskas, and Y. Deng, "Enhanced enzymatic hydrolysis of spruce by alkaline pretreatment at low temperature," Biotechnology and Bioengineering, vol. 99, pp. 1320-1328, April 2008.

[28] A. Abdul Aziz, K. Das, M. Husin, and A. Mokhtar, "Effect of physical and chemical pre-treatment on xylose and glucose production from oil palm press fiber," Journal of Oil Palm Research, vol. 14, pp. 10-17, December 2002.

[29] R. Sun, X. Song, R. Sun, and J. Jiang, "Effect of lignin content on enzymatic hydrolysis of furfural residue," BioResources, vol. 1, pp. 317-328, 2011.

[30] T. Y. Ding, S. L. Hii, and L. G. A. Ong, "Comparison of pretreatment strategies for conversion of coconut husk fiber to fermentable sugars," BioResources, vol. 7, pp. 1540-1547, 2012.

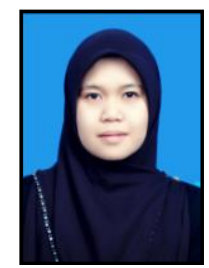

Nur Izzati Iberahim was born at Malacca, Malaysia in January 31, 1988. She received her Bachelor of Engineering in Biochemical Engineering in 2010 from Universiti Kebangsaan Malaysia (UKM), Bangi, Selangor.

Miss Nur Izzati Iberahim is a member of Institution of Chemical Engineers (IChemE). 